\begin{abstract}
Submitted:
10.02.2021

Accepted:

14.07.2021

Published:

29.11.2021

Keywords

ultrasound,

sensitivity,

specificity,

gouty arthritis,

meta-analysis

\section{Reliability of knee joint sonography in the evaluation of gouty arthritis}

\author{
Zafar Iqbal Anjum, Raham Bacha, Iqra Manzoor, Syed Amir Gilani \\ UIRSMIT, The University of Lahore, Pakistan \\ Correspondence: Iqra Manzoor, UIRSMIT, The University of Lahore, Pakistan; \\ e-mail:iqramanzoor36@gmail.com
}

DOI: $10.15557 / \mathrm{JoU} .2021 .0051$

Abstract

Objective: To determine the reliability of knee joint sonography in the evaluation of gouty arthritis. Methodology: A search of Google Scholar, PubMed, NCBI, MEDLINE, and Medscape databases, from 1988 up to 2020. The key search terms used were knee joint; knee joint ultrasound; gout; gouty arthritis, knee joint pain; sensitivity; specificity. The reviewer independently screened the titles and abstracts of the relevant articles and fulltext downloads to determine whether the inclusion or exclusion criteria were met. Results: In total, 103 articles were identified through the database search. In addition, 11 articles were identified through other sources. Then, screening was performed, and 9 articles were removed due to duplication. Further screening was done for 105 articles, and 27 articles were excluded due to insufficient information. Seventy-eight full-text articles were assessed for eligibility. A total of 13 full-text articles were excluded due to research performed on animals, as the study had been designed as a review of only human studies. Sixty-three studies were included that had a qualitative synthesis. Conclusion: The knee is a weightbearing joint and may be affected by a myriad of different pathological conditions, therefore a proper diagnosis is of prime importance for a proper management plan. Ultrasound is a non-invasive, radiation-free, and readily available modality that has high sensitivity and specificity in the evaluation of gouty arthritis.
\end{abstract}

\section{Introduction}

The knee is a weight-bearing joint and can be affected by several pathological conditions ranging from a simple muscular sprain and strain to tendon and ligament tears, and bone fractures. Knee joint pain and disability is one of the most common musculoskeletal disorders that accounts for the greatest proportion of visits to orthopedic clinics ${ }^{(1)}$. Knee joint sonography is the second common examination technique after shoulder sonography. It consumes a substantial amount of budget every year. Gouty arthritis is one of the widespread causes of knee pain and disability ${ }^{(2)}$.

Monosodium urate (MSU) crystal deposition in articular or periarticular tissues and the renal tract is linked to the clinical manifestations of gout. Usually, the natural history of articular gout consists of three stages: asymptomatic hyperuricemia, outbreaks of asymptomatic acute gout attacks, and chronic gout arthritis ${ }^{(3)}$. In comparison, it is potentially easier to treat and cure gout in cases with a relatively low urate crystal load, though there is insufficient knowledge on the occurrence of urate deposits in the joints of patients with uncomplicated gout ${ }^{(4)}$.

Ultrasonography (US) is a beneficial method for detecting deposits of intra-articular urate ${ }^{(5)}$. The double contour (DC) sign formed by the deposition of urate crystals on the surface of the articular cartilage and hyperechoic cloudy areas representing urate deposits inside the joint and tendons or soft tissues are considered to be two characteristic sonographic features of gout ${ }^{(5-9)}$. Ultrasound scanning is routinely performed to diagnose gouty arthritis but a high degree of discordance is found in the literature as to its reliability. A review and pooling of the results of studies in the literature were needed to gain insights into the reliability of the examination.

\section{Material and methods}

A search of Google Scholar, PubMed, NCBI, MEDLINE, and Medscape databases, from 1988 up to 2020 was performed. 
Tab. 1. Variables of the study (N/A represents that no data related to particular variables were available in the studies)

\begin{tabular}{|c|c|c|c|c|c|c|c|}
\hline No. & Author (year) & Sensitivity & Specificity & Country & Sample size & Disease & Journal \\
\hline 1 & Cajas et al. (1988)(22) & $\mathrm{N} / \mathrm{A}$ & $\mathrm{N} / \mathrm{A}$ & Italy & 20 & Gout & Acta Radiol \\
\hline 2 & Nalbant et al. $(2003)^{(23)}$ & $\mathrm{N} / \mathrm{A}$ & $\mathrm{N} / \mathrm{A}$ & USA & 26 & Gout & The Journal of Rheumatology \\
\hline 3 & Grassi et al. (2006)(24) & $\mathrm{N} / \mathrm{A}$ & $\mathrm{N} / \mathrm{A}$ & Italy & 60 & Gout & Semin Arthritis Rheum \\
\hline 4 & Rettenbacher et al. (2007)(25) & 96 & 73 & Austria & 105 & Gout & European Radiology \\
\hline 5 & Thiele \& Schlesinger $(2007)^{(7)}$ & N/A & $\mathrm{N} / \mathrm{A}$ & USA & 23 & Gout & Rheumatology \\
\hline 6 & Wright et al. $(2007)^{(6)}$ & $67 \%$ & $71 \%$ & UK & 39 & Gout & Annals of the Rheumatic Diseases \\
\hline 7 & Filippucci et al. $(2008)^{(8)}$ & $43.70 \%$ & $99 \%$ & France & 132 & Gout & Osteoarthritis and Cartilage \\
\hline 8 & lagnocco et al. (2011)(26) & $\mathrm{N} / \mathrm{A}$ & $\mathrm{N} / \mathrm{A}$ & Italy & $\mathrm{N} / \mathrm{A}$ & Gout & Semin Ultrasound CT MR \\
\hline 9 & Perez-Ruiz et al. (2009) ${ }^{(5)}$ & $96 \%$ & $73 \%$ & Spain & $\mathrm{N} / \mathrm{A}$ & Gout & Arthritis Research \& Therapy \\
\hline 10 & Carter et al. $(2009)^{(27)}$ & N/A & N/A & USA & 27 & Gout & Rheumatology \\
\hline 11 & Filippucci et al. (2010) ${ }^{(28)}$ & N/A & N/A & Italy & 100 & Gout & Clin Exp Rheumatol \\
\hline 12 & Thiele $(2011)^{(14)}$ & $96 \%$ & $83.70 \%$ & New York & N/A & Gout & Current Rheumatology Reports \\
\hline 13 & Pineda et al. (2011) & N/A & $\mathrm{N} / \mathrm{A}$ & Mexico & 102 & Gouty Arthritis & Arthritis Research \& Therapy \\
\hline 14 & Howard et al. $(2011)^{(30)}$ & $\mathrm{N} / \mathrm{A}$ & $\mathrm{N} / \mathrm{A}$ & New York & 50 & Gout & Arthritis Care \& Research \\
\hline 15 & de Ávila Fernandes et al. (2011) & $83.30 \%$ & $61.60 \%$ & Brazil & 31 & Gout & Skeletal Radiology \\
\hline 16 & Filippucci et al. (2011) & $85 \%$ & $79 \%$ & Italy & 50 & Gout & European Radiology \\
\hline 17 & Ottaviani et al. $(2011)^{(34)}$ & $75 \%$ & $62.50 \%$ & France & 15 & Gout & Experimental Rheumatology \\
\hline 18 & Choi et al. $(2011)^{(35)}$ & $78 \%$ & $93 \%$ & USA & 40 & Gout & Annals of Rheumatic Diseases \\
\hline 19 & Dalbeth et al. $(2011)^{(36)}$ & $81 \%$ & $76 \%$ & USA & 33 & Gout & Annals of Rheumatic Diseases \\
\hline 20 & Glazebrook et al. (2011) & $100 \%$ & $89 \%$ & New York & 12 & Gout & Radiology \\
\hline 21 & De Miguel et al. $(2011)^{(32)}$ & $43 \%$ & $99 \%$ & Spain & 26 & Gout & Annals of Rheumatic Diseases \\
\hline 22 & Roddy et al. $(2013)^{(38)}$ & $90 \%$ & $93 \%$ & UK & 40 & Gout & Joint Bone Spine \\
\hline 23 & McQueen et al. (2012) ${ }^{(39)}$ & $\mathrm{N} / \mathrm{A}$ & $\mathrm{N} / \mathrm{A}$ & New Zealand & & Gout & Postgraduate Medical Journal \\
\hline 24 & Ottaviani et al. (2012)(40) & $67 \%$ & $100 \%$ & France & 500 & Gout & Clin Exp Rheumatol \\
\hline 25 & Girish et al. $(2013)^{(41)}$ & N/A & $\mathrm{N} / \mathrm{A}$ & USA & $\mathrm{N} / \mathrm{A}$ & Gout & Hindawi \\
\hline 26 & Bergner et al. $(2013)^{(42)}$ & $92 \%$ & $72 \%$ & Germany & 103 & Gout & Annals of the Rheumatic Diseases \\
\hline 27 & Huppertz et al. (2014) ${ }^{(43)}$ & $84.60 \%$ & $85.70 \%$ & Berlin & 60 & Gout & Rheumatology International \\
\hline 28 & Zhang et al. $(2014)^{(44)}$ & $95.59 \%$ & $68 \%$ & China & 32 & Gout & Journal of Sichuan University \\
\hline 29 & Lamers-Karnebeek et al. (2014)(45) & $77 \%$ & $96 \%$ & Netherlands & 54 & Gout & Clinical Rheumatology \\
\hline 30 & Naredo et al. (2014) $)^{(46)}$ & $84.60 \%$ & $83.30 \%$ & Spain & 91 & Gout & Annals of the Rheumatic Diseases \\
\hline 31 & Löffler et al. (2015) ${ }^{(20)}$ & $85 \%$ & $80 \%$ & Germany & 225 & Gout & Journal of Rheumatology \\
\hline 32 & Atik et al. $(2015)^{(47)}$ & $46.30 \%$ & $99 \%$ & Italy & $\mathrm{N} / \mathrm{A}$ & Gout & Medical Ultrasonography \\
\hline 33 & Zufferey et al. (2015) & $60 \%$ & $90 \%$ & Switzerland & 109 & Gout & Arthritis Research \& Therapy \\
\hline 34 & Bongartz et al. $(2015)^{(49)}$ & $90 \%$ & $83 \%$ & USA & 40 & Gout & Annals of Rheumatic Diseases \\
\hline 35 & Diekhoff et al. (2015) & $100 \%$ & $100 \%$ & Germany & 3 & Gout & Skeletal radiology \\
\hline 36 & Ogdie et al. $(2017)^{(18)}$ & $76.90 \%$ & $84.30 \%$ & New Zealand & 824 & Gout & Arthritis and Rheumatology \\
\hline 37 & Das et al. (2016) & $86.25 \%$ & $100 \%$ & India & 38 & Gout & Modern Rheumatology \\
\hline 38 & Elsama et al. (2016) & $85.90 \%$ & $86.70 \%$ & Germany & 100 & Gout & Ultrasound Med Biol \\
\hline 39 & Zhu et al. (2017) & $97.14 \%$ & $74.29 \%$ & China & 195 & Gout & Journal of Ultrasound in Medicine \\
\hline 40 & Elsaman et al. (2016) ${ }^{(19)}$ & $86 \%$ & $87 \%$ & Egypt & 100 & Gout & Ultrasound Med Biol \\
\hline 41 & Ahmad et al. (2016) ${ }^{(53)}$ & $100 \%$ & $48 \%$ & India & 30 & Gout & Int J Rheum Dis \\
\hline 42 & Ventura-Ríos et al. $(2016)^{(54)}$ & $69.60 \%$ & $92 \%$ & Mexico & 35 & Gout & Clinical Rheumatology \\
\hline 43 & Stewart et al. (2017) $)^{(55)}$ & $\mathrm{N} / \mathrm{A}$ & $\mathrm{N} / \mathrm{A}$ & New Zealand & 86 & Gout & Journal of Foot and Ankle Research \\
\hline 44 & Stewart et al. $(2017)^{(56)}$ & N/A & N/A & New Zealand & 34 & Gout & Arthritis Care \& Research \\
\hline 45 & Das et al. $(2017)^{(12)}$ & $69.40 \%$ & $100 \%$ & India & 62 & Gout & Int J Rheum Dis \\
\hline 46 & Lee \& Song $(2017)^{(57)}$ & $65.10 \%$ & $89.00 \%$ & Korea & 938 & Gout & Semin Arthritis Rheum \\
\hline 47 & Pattamapaspong et al. $(2017)^{(58)}$ & $58 \%$ & $92 \%$ & Thailand & 89 & Gout & Skeletal Radiology \\
\hline 48 & Zhang et al. (2018) & $66 \%$ & $92 \%$ & China & 13 & Gout & PLOS ONE \\
\hline 49 & Tekaya et al. (2018) & $\mathrm{N} / \mathrm{A}$ & $\mathrm{N} / \mathrm{A}$ & Tunisia & 1 & Gout & Egyptian Rheumatologist \\
\hline 50 & Bhadu et al. $(2018)^{(60)}$ & $87.20 \%$ & $84 \%$ & India & 47 & Gout & Int J Rheum Dis \\
\hline 51 & Gamala et al. $(2018)^{(61)}$ & $\mathrm{N} / \mathrm{A}$ & N/A & Netherlands & 147 & Gout & Clinical Rheumatology \\
\hline 52 & Dalbeth \& Doyle (2018) $)^{(62)}$ & N/A & N/A & New Zealand & 60 & Gout & Rheumatology \\
\hline 53 & Jia et al. $(2018)^{(63)}$ & $80.88 \%$ & $88.24 \%$ & China & 221 & Gout & Clinical Rheumatology \\
\hline 54 & Ramon et al. (2018) & $90 \%$ & $80 \%$ & France & 1502 & Gout & Clinical Rheumatology \\
\hline
\end{tabular}




\begin{tabular}{|c|c|c|c|c|c|c|c|}
\hline 55 & Di Matteo et al. (2019) & $\mathrm{N} / \mathrm{A}$ & $\mathrm{N} / \mathrm{A}$ & Portugal & 40 & Gout & Joint Bone Spine \\
\hline 56 & Cazenave et al. $(2019)^{(66)}$ & $\mathrm{N} / \mathrm{A}$ & $\mathrm{N} / \mathrm{A}$ & Germany & 13 & Gout & Rheumatology International \\
\hline 57 & Murayama et al. (2019) ${ }^{(67)}$ & $\mathrm{N} / \mathrm{A}$ & $\mathrm{N} / \mathrm{A}$ & N/A & 1 & Gout & Mod Rheumatol Case Rep \\
\hline 58 & Micu \& Dogaru (2019) ${ }^{(68)}$ & $\mathrm{N} / \mathrm{A}$ & $\mathrm{N} / \mathrm{A}$ & $\mathrm{N} / \mathrm{A}$ & 1 & Gout & Clinical Rheumatology \\
\hline 59 & Persons \& Kissin $(2020)^{(69)}$ & $\mathrm{N} / \mathrm{A}$ & $\mathrm{N} / \mathrm{A}$ & USA & 1 & Gout & J Med Ultrasound \\
\hline 60 & Sakellariou et al. $(2020)^{(70)}$ & $79 \%$ & $69 \%$ & Italy & 943 & Gout & Frontiers in Medicine \\
\hline
\end{tabular}

The key search terms used were knee joint; knee joint ultrasound; gout; gouty arthritis, knee joint pain; sensitivity; specificity. The reviewer independently screened the titles and abstracts of the relevant articles and full-text downloads to determine whether the inclusion or exclusion criteria were met. Any disagreement was resolved through a consensus. The studies were eligible if they included information about gout and the role of ultrasound in the diagnosis of gouty arthritis. Studies involving research on animals were excluded from the review process. The eligible studies were categorized, and then data analysis was performed according to specific pathological conditions. This literature review retrieved study sample size, gouty arthritis, sensitivity, specificity of the ultrasound in the diagnosis of gout. From all the data retrieved, descriptive statistics were compiled for further analysis. A table was created, with predefined subgroups, for all the variables included in the study (Tab. 1). The variables included the year of the study, first author of the research article, country, sensitivity, specificity, sample size, disease, and journal name. The studies were included if complete information was available for all the variables in a human study. The studies were excluded if incomplete information was given about the variables of the study. In total, 103 articles were identified through the database search. In addition, 11 articles were identified through other sources. Then, screening was performed, and 9 articles were removed due to duplication. Further screening was performed for 105 articles, and 27 articles were excluded due to insufficient information. Seventy-eight full-text articles were assessed for eligibility. A total of 13 full-text articles were excluded due to research performed on animals, as the study had been designed as a review of only human studies. Sixty-three studies were included that had a qualitative synthesis. In addition, 63 quantitative syntheses were included (meta-analysis). The flow diagram depicts the flow of information through the different phases of the systematic review. It maps out the number of records identified, included, and excluded, and the reasons for their exclusion (Fig. 1).
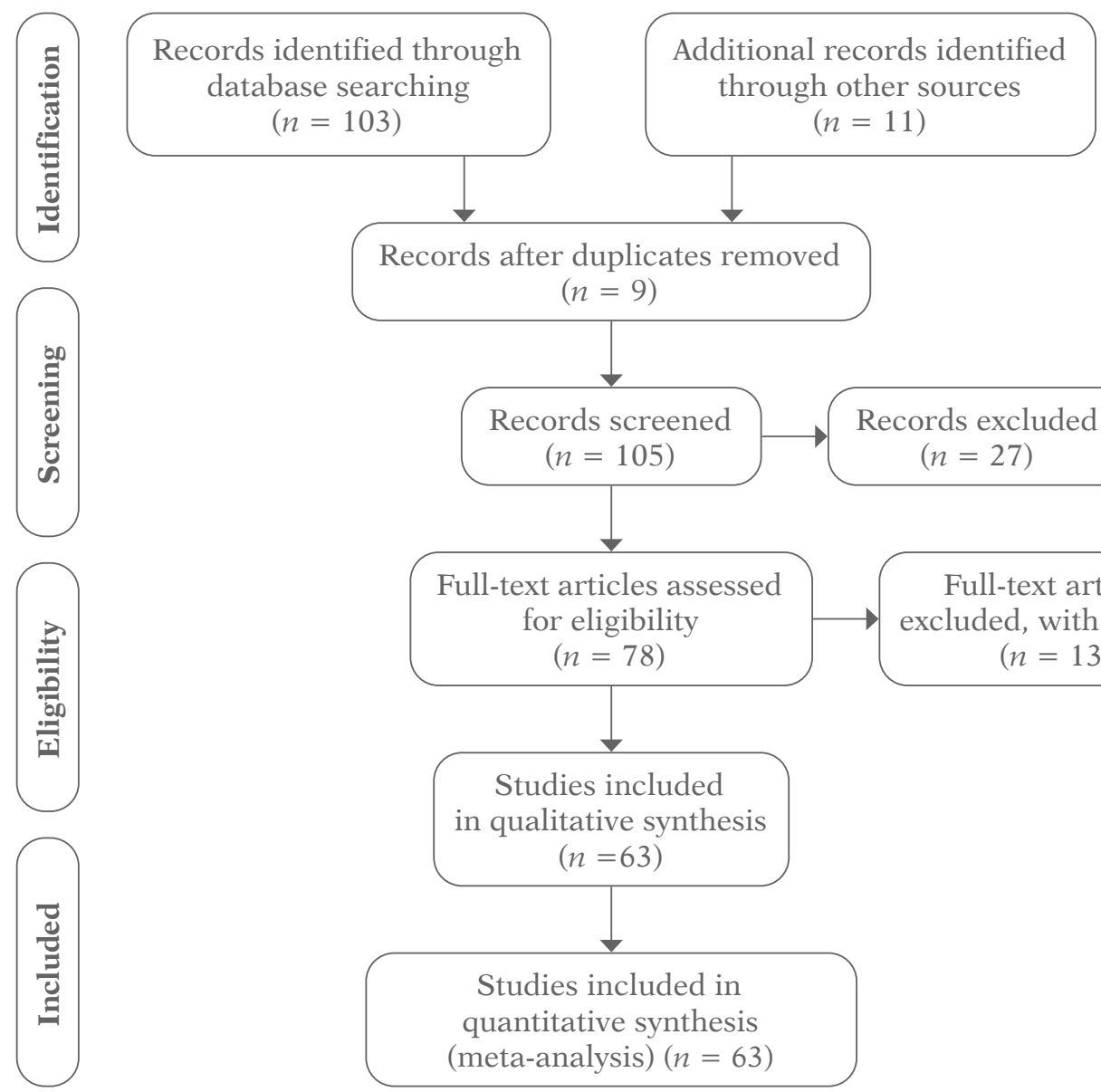

Records after duplicates removed

$(n=9)$

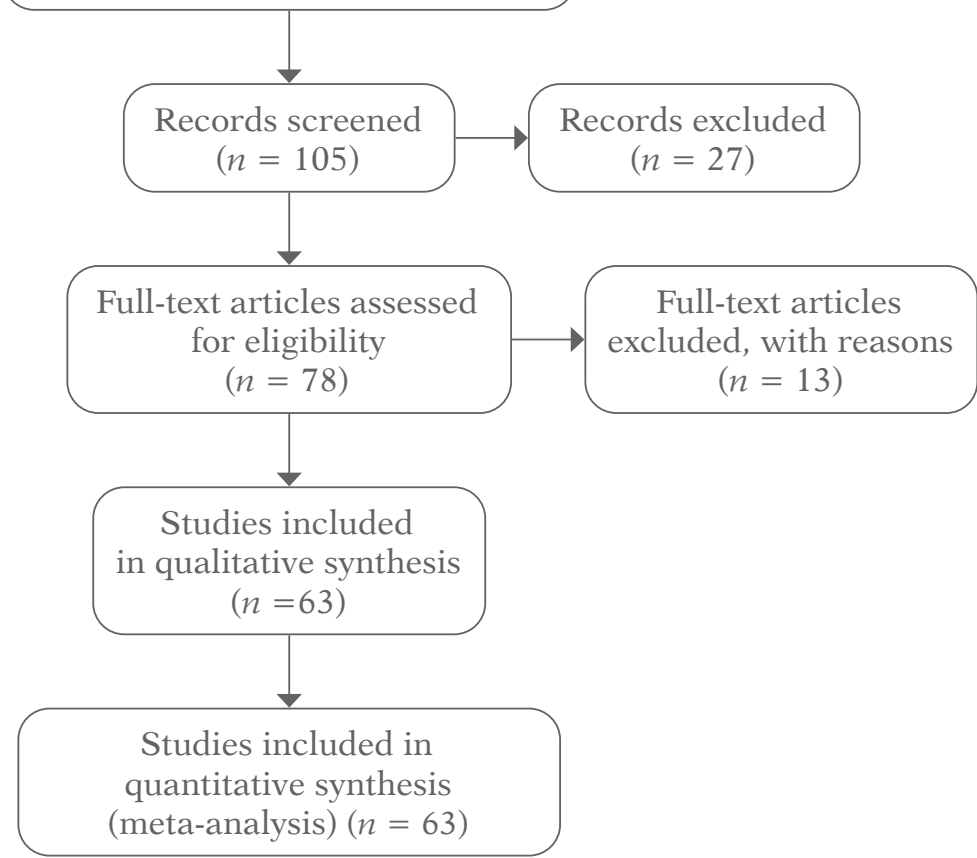

Fig. 1. PRISMA 2009 Flow Diagram 


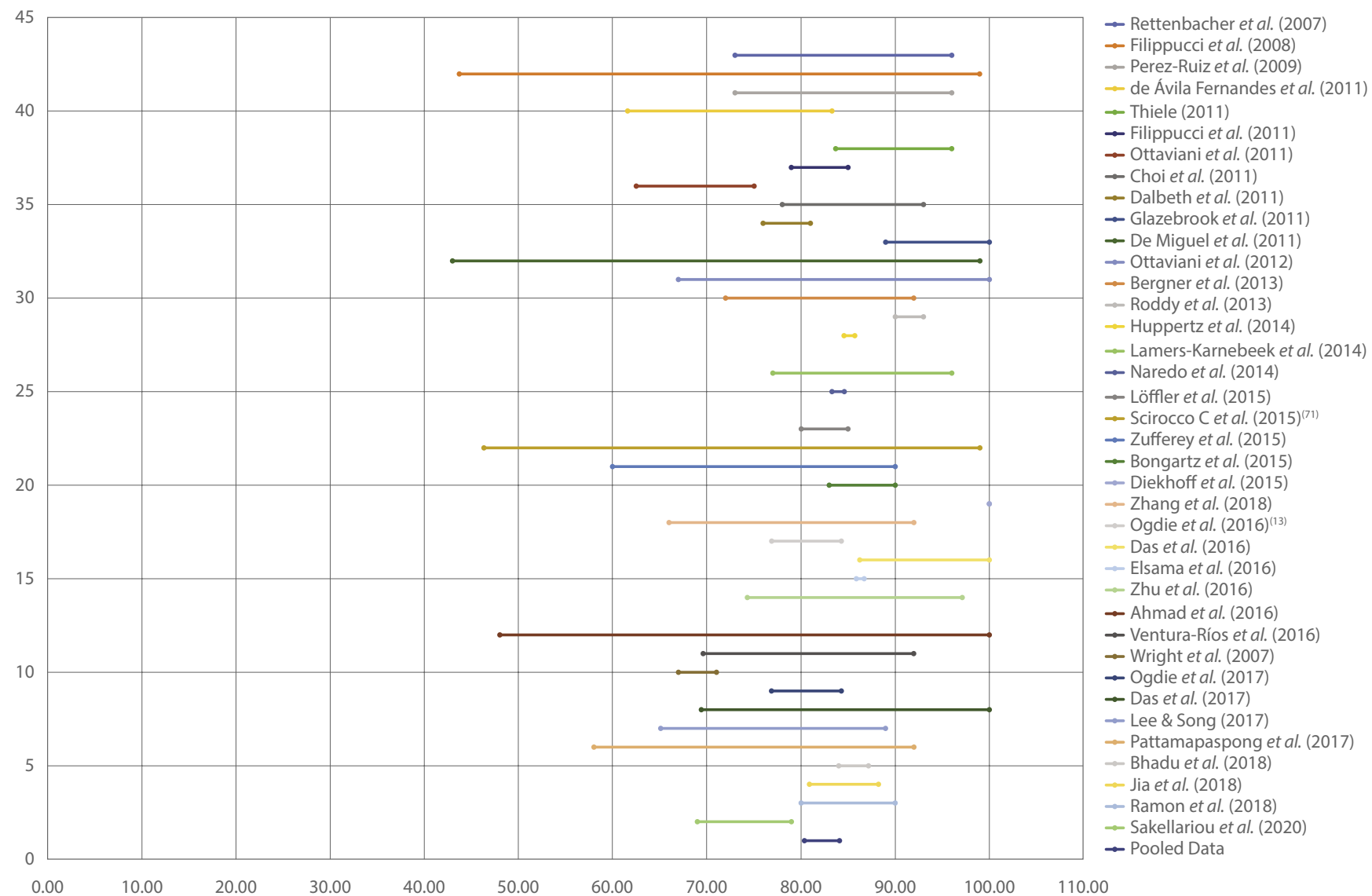

Fig. 2. Forest plot showing the sensitivities and specificities of the studies, and pooled results (represented with a thick horizontal line at the bottom of the plot)

\section{Results}

The articles included in the literature review were published in 1988-2020. The disease under study was gouty arthritis which causes pain in the knee joint and was confirmed with the help of ultrasonography (Tab. 1). A forest plot was made for each study having the sensitivity and specificity of gouty arthritis. The pooled sensitivity of the ultrasound in the diagnosis of gouty arthritis in the patients having knee joint pain was $80.35 \%$, while the specificity was $84.09 \%$ (Fig. 2).

\section{Discussion}

Gout is a prevalent arthritic disorder that affects around 1\% of the population. In men, the prevalence is higher, and rising with age. The pathogenesis of gout involves disturbed purine metabolism, reduced uric acid renal excretion, elevated levels of uric acid in the blood, and deposition of crystals of monosodium urate (MSU) in the joints and soft tissues ${ }^{(10)}$. Episodic acute monoarthritis of the first metatarsophalangeal joint (MTP) with overlying erythema is the usual gout presentation. However, the clinical appearance can become atypical as the disease progresses; for example, polyarticular attacks involving the hand joints and prolonged arthritis duration may occur ${ }^{(11)}$. Needle aspiration of joint effusion and detection of MSU crystals by polarizing microscopy is the gold standard procedure for diagnosing gout ${ }^{(12)}$. However, in a subset of arthritic patients, arthrocentesis is not done, and these patients frequently undergo empirical treatment with an indefinite diagnosis ${ }^{(10)}$. In several joint diseases, ultrasonography (US) is a helpful evaluation tool, offering assistance in disease detection, assessment of results, and aspiration and local injection procedures ${ }^{(13)}$. Ultrasound has also been found to be a useful modality for the diagnosis of gout, as early deposition of MSU crystals can be identified in certain joint structures, such as hyaline cartilage surface and synovium ${ }^{(14)}$. It is also possible to use the US to measure synovial thickness, synovial effusion, and bone degradation. Power Doppler US may evaluate synovial inflammation ${ }^{(15)}$. The diagnostic utility of US for gout, however, varies across studies; thus, additional research is needed to confirm the usefulness of US in diagnosing gout ${ }^{(16)}$. Such research would have to evaluate the characteristic sonographic features of gouty arthritis and to assess the diagnostic importance of gouty arthritis in the US. While gout is widespread, an actual diagnosis of crystals is rarely pursued ${ }^{(16)}$. Polarizing microscopy, the diagnostic gold standard, joint aspiration and crystal analysis require technical expertise and equipment. Consequently, patient-friendly, effective modalities for the diagnostic work-up would be highly desirable. Ideally, such a test would be non-invasive, affordable, effective, highly sensitive and precise, and would involve repeated testing to determine patient response to the 
procedures. Imaging, such as classical (CR) radiography, CT, MRI and ultrasound (US) are currently used for diagnosis. Guidance on the protocol and evaluation of the treatment response in gout. Ultrasonography is a readily accessible technique worldwide ${ }^{(17)}$. US was used for assessing the crystalline deposits present in and around joints ${ }^{(18)}$. The urate of monosodium (MSU) tophi can best be sonographically visualized ${ }^{(19)}$. While it is possible to see calcified concrements on CR, MSU tophi are not commonly seen on $\mathrm{CR}^{(20)}$. Ultrasound was found to be more sensitive in detecting bony erosions in rheumatoid arthritis when compared with radiography ${ }^{(21)}$. According to the results of our study ultrasound has high sensitivity and specificity in the diagnosis of gouty arthritis.

\section{References}

1. Sudoł-Szopińska I, Pracoń G: Diagnostic imaging of psoriatic arthritis. Part II: magnetic resonance imaging and ultrasonography. J Ultrason 2016; 16: 163-174.

2. Singh K, Gupta K, Kaur S: High resolution ultrasonography of the tibial nerve in diabetic peripheral neuropathy. J Ultrason 2017; 17: 246-252.

3. Richette P, Bardin T: Gout. Lancet 2010; 375: 318-328.

4. Sudoł-Szopińska I, Jans L, Teh J: Rheumatoid arthritis: what do MRI and ultrasound show. J Ultrason 2017; 17: 5-16.

5. Perez-Ruiz F, Dalbeth N, Urresola A, de Miguel E, Schlesinger N: Imaging of gout: findings and utility. Arthritis Res Ther 2009; 11: 232.

6. Wright SA, Filippucci E, McVeigh C, Grey A, McCarron M, Grassi W et al.: High-resolution ultrasonography of the first metatarsal phalangeal joint in gout: a controlled study. Ann Rheum Dis 2007; 66: 859-864.

7. Thiele RG, Schlesinger N: Diagnosis of gout by ultrasound. Rheumatology 2007; 46: 1116-1121.

8. Filippucci E, Gutierrez M, Georgescu D, Salaffi F, Grassi W: Hyaline cartilage involvement in patients with gout and calcium pyrophosphate deposition disease. An ultrasound study. Osteoarthritis Cartilage 2009; 17: $178-181$

9. Sconfienza L, Silvestri E, Bartolini B, Garlaschi G, Cimmino MA: Sonoelastography may help in the differential diagnosis between rheumatoid nodules and tophi. Clin Exp Rheumatol 2010; 28: 144-145.

10. Neogi T, Jansen TLTA, Dalbeth N, Fransen J, Schumacher HR, Berendsen D et al: 2015 gout classification criteria: an American College of Rheumatology/European League Against Rheumatism collaborative initiative. Arthritis Rheumatol 2015; 67: 2557-2568.

11. Dalbeth N, Doyle A, McQueen FM: Imaging in gout: insights into the pathological features of disease. Curr Opin Rheumatol 2012; 24: 132-138.

12. Das S, Ghosh A, Ghosh P, Lahiri D, Sinhamahapatra P, Basu K: Sensitivity and specificity of ultrasonographic features of gout in intercritical and chronic phase. Int J Rheum Dis 2017; 20: 887-893.

13. Ogdie A, Taylor WJ, Weatherall M, Fransen J, Jansen TL, Neogi T et al.: Imaging modalities for the classification of gout: systematic literature review and meta-analysis. Ann Rheum Dis 2015; 74: 1868-1874.

14. Thiele RG: Role of ultrasound and other advanced imaging in the diagnosis and management of gout. Curr Rheum Rep 2011; 13: 146-153.

15. Gutierrez M, Schmidt WA, Thiele RG, Keen HI, Kaeley GS, Naredo E et al.: International consensus for ultrasound lesions in gout: results of Delphi process and web-reliability exercise. Rheumatology 2015; 54: 1797-1805.

16. Chowalloor PV, Keen HI: A systematic review of ultrasonography in gout and asymptomatic hyperuricaemia. Ann Rheum Dis 2013; 72: 638-645.

17. Liberati A, Altman DG, Tetzlaff J, Mulrow C, Gøtzsche PC, Ioannidis JP et al.: The PRISMA statement for reporting systematic reviews and meta-analyses of studies that evaluate health care interventions: explanation and elaboration. J Clin Epidemiol 2009; 62: e1-e34.

18. Ogdie A, Taylor WJ, Neogi T, Fransen J, Jansen TL, Schumacher HR et al.: Performance of ultrasound in the diagnosis of gout in a multicenter study: comparison with monosodium urate monohydrate crystal analysis as the gold standard. Arthritis Rheumatol 2017; 69: 429-438.

\section{Conclusion}

The knee is a weight-bearing joint and may be affected by a myriad of different pathological conditions. Therefore, a proper diagnosis is of prime importance for a proper management plan. Ultrasound is a non-invasive, radiation-free, and readily available modality characterized by high sensitivity and specificity in the evaluation of gouty arthritis.

\section{Conflict of interest}

The authors have no conflict of interest.

19. Elsaman AM, Muhammad EM, Pessler F: Sonographic findings in gouty arthritis: diagnostic value and association with disease duration. Ultrasound Med Biol 2016; 42: 1330-1136.

20. Löffler C, Sattler H, Peters L, Löffler U, Uppenkamp M, Bergner R: Distinguishing gouty arthritis from calcium pyrophosphate disease and other arthritides. J Rheumatol 2015; 42: 513-520.

21. Grassi W, Filippucci E, Farina A, Salaffi F, Cervini C: Ultrasonography in the evaluation of bone erosions. Ann Rheum Dis 2001; 60: 98-104.

22. Cajas LJ, Casallas A, Medina YF, Quintana G, Rondón F: Pannus and rheumatoid arthritis: historic and pathophysiological evolution. Rev Colomb Reumatol 2019; 26: 118-128.

23. Nalbant S, Corominas H, Hsu B, Chen LX, Schumacher HR, Kitumnuaypong T: Ultrasonography for assessment of subcutaneous nodules. J Rheumatol 2003; 30: 1191-1195.

24. Grassi W, Meenagh G, Pascual E, Filippucci E: „Crystal clear”-sonographic assessment of gout and calcium pyrophosphate deposition disease. Semin Arthritis Rheum 2006; 36: 197-202.

25. Rettenbacher T, Ennemoser S, Weirich H, Ulmer H, Hartig F, Klotz W et al.: Diagnostic imaging of gout: comparison of high-resolution US versus conventional X-ray. Eur Radiol 2008; 18: 621-630.

26. Iagnocco A, Ceccarelli F, Perricone C, Valesini G: The role of ultrasound in rheumatology. Semin Ultrasound CT MRI 2011; 32: 66-73.

27. Carter JD, Kedar RP, Anderson SR, Osorio AH, Albritton NL, Gnanashanmugam S et al.: An analysis of MRI and ultrasound imaging in patients with gout who have normal plain radiographs. Rheumatology 2009; 48: 1442-1446.

28. Filippucci E, Scirè CA, Delle Sedie A, Iagnocco A, Riente L, Meenagh G et al.: Ultrasound imaging for the rheumatologist XXV. Sonographic assessment of the knee in patients with gout and calcium pyrophosphate deposition disease. Clin Exp Rheumatol 2010; 28: 2-5.

29. Pineda C, Amezcua-Guerra LM, Solano C, Rodriguez-Henríquez P, Hernández-Díaz C, Vargas A et al.: Joint and tendon subclinical involvement suggestive of gouty arthritis in asymptomatic hyperuricemia: an ultrasound controlled study. Arthritis Res Ther 2011; 13: R4.

30. Howard RG, Pillinger MH, Gyftopoulos S, Thiele RG, Swearingen CJ, Samuels J: Reproducibility of musculoskeletal ultrasound for determining monosodium urate deposition: concordance between readers. Arthritis Care Res 2011; 63: 1456-1462.

31. de Ávila Fernandes E, Kubota ES, Sandim GB, Mitraud SA, Ferrari AJ, Fernandes AR: Ultrasound features of tophi in chronic tophaceous gout. Skeletal Radiol 2011; 40: 309-315.

32. De Miguel E, Puig JG, Castillo C, Peiteado D, Torres RJ, Martín-Mola E: Diagnosis of gout in patients with asymptomatic hyperuricaemia: a pilot ultrasound study. Ann Rheum Dis 2012; 71: 157-158.

33. Filippucci E, Meenagh G, Delle Sedie A, Sakellariou G, Iagnocco A, Riente L et al.: Ultrasound imaging for the rheumatologist XXXVI. Sonographic assessment of the foot in gout patients. Clin Exp Rheumatol 2011; 29: 901-905.

34. Ottaviani S, Allard A, Bardin T, Richette P: An exploratory ultrasound study of early gout. Clin Exp Rheumatol 2011; 29: 816-821. 
35. Choi HK, Burns LC, Shojania K, Koenig N, Reid G, Abufayyah M et al:: Dual energy CT in gout: a prospective validation study. Ann Rheum Dis 2012; 71: 1466-1471.

36. Dalbeth N, Schauer C, MacDonald P, Perez-Ruiz F, Schumacher HR, Hamburger $\mathrm{S}$ et al.: Methods of tophus assessment in clinical trials of chronic gout: a systematic literature review and pictorial reference guide. Ann Rheum Dis 2011; 70: 597-604.

37. Glazebrook KN, Guimarães LS, Murthy NS, Black DF, Bongartz T, Manek NJ et al.: Identification of intraarticular and periarticular uric acid crystals with dual-energy CT: initial evaluation. Radiology 2011; 261: 516-524.

38. Roddy E, Menon A, Hall A, Datta P, Packham J: Polyarticular sonographic assessment of gout: a hospital-based cross-sectional study. Joint Bone Spine 2013; 80: 295-300.

39. McQueen FM, Reeves Q, Dalbeth N: New insights into an old disease: advanced imaging in the diagnosis and management of gout. Postgrad Med J 2013; 89: 87-93.

40. Ottaviani S, Richette P, Allard A, Ora J, Bardin T: Ultrasonography in gout: a case-control study. Clin Exp Rheumatol 2012; 30: 499-504.

41. Girish G, Melville DM, Kaeley GS, Brandon CJ, Goyal JR, Jacobson JA et al.: Imaging appearances in gout. Arthritis 2013; 2013.

42. Bergner R, Peters L, Schmitt V, Sattler H, Löffler C: SAT0382 Arthrosonographic Findings in Crystal Arthropathies. Ann Rheum Dis 2013; 72 (Suppl 3): A713.

43. Huppertz A, Hermann K-GA, Diekhoff T, Wagner M, Hamm B, Schmidt WA: Systemic staging for urate crystal deposits with dual-energy CT and ultrasound in patients with suspected gout. Rheumatol Int 2014; 34: 763-771.

44. Zhang Q, Gao F, Sun W, Ma J, Cheng L, Li Z: The diagnostic performance of musculoskeletal ultrasound in gout: a systematic review and meta-analysis. PloS One 2018; 13: e0199672.

45. Lamers-Karnebeek F, Van Riel P, Jansen T: Additive value for ultrasonographic signal in a screening algorithm for patients presenting with acute mono-/oligoarthritis in whom gout is suspected. Clin Rheumatol 2014; 33: 555-559.

46. Naredo E, Uson J, Jiménez-Palop M, Martínez A, Vicente E, Brito E et al.: Ultrasound-detected musculoskeletal urate crystal deposition: which joints and what findings should be assessed for diagnosing gout? Ann Rheum Dis 2014; 73: 1522-1528.

47. Atik OŞ, Ergişi Y, Ayanoğlu T, Tokgöz MA, Sezgin EA, Göçün PU: Is it easy to clinically distinguish inflammatory arthritis of bacterial origin from monoarthritis attacks of gout disease? Eklem Hastalik Cerrahisi 2016; 27: 167-170.

48. Zufferey P, Valcov R, Fabreguet I, Dumusc A, Omoumi P, So A: A prospective evaluation of ultrasound as a diagnostic tool in acute microcrystalline arthritis. Arthritis Res Ther 2015; 17: 188.

49. Bongartz T, Glazebrook KN, Kavros SJ, Murthy NS, Merry SP, Franz WB et al.: Dual-energy CT for the diagnosis of gout: an accuracy and diagnostic yield study. Ann Rheum Dis 2015; 74: 1072-1077.

50. Diekhoff T, Ziegeler K, Feist E, Kiefer T, Mews J, Hamm B et al.: First experience with single-source dual-energy computed tomography in six patients with acute arthralgia: a feasibility experiment using joint aspiration as a reference. Skeletal Radiol 2015; 44: 1573-1577.

51. Das S, Goswami RP, Ghosh A, Ghosh P, Lahiri D, Basu K: Temporal evolution of urate crystal deposition over articular cartilage after successful urate-lowering therapy in patients with gout: an ultrasonographic perspective. Mod Rheumatol 2017; 27: 518-523.

52. Zhu L, Zheng S, Wang W, Zhou Q, Wu H: Combining hyperechoic aggregates and the double-contour sign increases the sensitivity of sonography for detection of monosodium urate deposits in gout. J Ultrasound Med 2017; 36: 935-940.
53. Ahmad Z, Gupta AK, Sharma R, Bhalla AS, Kumar U, Sreenivas V: Dual energy computed tomography: a novel technique for diagnosis of gout. Int J Rheum Dis 2016; 19: 887-896.

54. Ventura-Ríos L, Sánchez-Bringas G, Pineda C, Hernández-Díaz C, Reginato A, Alva $\mathrm{M}$ et al.: Tendon involvement in patients with gout: an ultrasound study of prevalence. Clin Rheumatol 2016; 35: 2039-2044.

55. Stewart S, Dalbeth N, Vandal AC, Allen B, Miranda R, Rome K: Are ultrasound features at the first metatarsophalangeal joint associated with clinically-assessed pain and function? A study of people with gout, asymptomatic hyperuricaemia and normouricaemia. J Foot Ankle Res 2017; 10: 22.

56. Stewart S, Dalbeth N, Vandal AC, Allen B, Miranda R, Rome K: Ultrasound features of the first metatarsophalangeal joint in gout and asymptomatic hyperuricemia: comparison with normouricemic individuals. Arthritis Care Res 2017; 69: 875-883.

57. Lee YH, Song GG: Diagnostic accuracy of ultrasound in patients with gout: a meta-analysis. Semin Arthritis Rheum 2018; 47: 703-709.

58. Pattamapaspong N, Vuthiwong W, Kanthawang T, Louthrenoo W: Value of ultrasonography in the diagnosis of gout in patients presenting with acute arthritis. Skeletal Radiol 2017; 46: 759-767.

59. Tekaya R, Tekaya AB, Saidane O, Said HB, Gaja A, Sahli H et al.: Tophaceous hip gouty arthritis revealing asymptomatic axial gout. Egyptian Rheumatol 2018; 40: 209-212.

60. Bhadu D, Das SK, Wakhlu A, Dhakad U, Sharma M: Ultrasonographic detection of double contour sign and hyperechoic aggregates for diagnosis of gout: two sites examination is as good as six sites examination. Int J Rheum Dis 2018; 21: 523-531.

61. Gamala M, Linn-Rasker S, Nix M, Heggelman B, Van Laar J, Pasker-de Jong $\mathrm{P}$ et al.: Gouty arthritis: decision-making following dual-energy CT scan in clinical practice, a retrospective analysis. Clin Rheumatol 2018; 37: 1879-1884.

62. Dalbeth N, Doyle AJ: Imaging tools to measure treatment response in gout. Rheumatology 2018; 57 (suppl_1): i27-i34.

63. Jia E, Zhu J, Huang W, Chen X, Li J: Dual-energy computed tomography has limited diagnostic sensitivity for short-term gout. Clin Rheumatol 2018; 37: 773-777.

64. Ramon A, Bohm-Sigrand A, Pottecher P, Richette P, Maillefert J-F, Devilliers $\mathrm{H}$ et al.: Role of dual-energy CT in the diagnosis and follow-up of gout: systematic analysis of the literature. Clin Rheumatol 2018; 37: 587-595.

65. Di Matteo A, Filippucci E, Cipolletta E, Musca A, Di Donato E, Martire V et al.: Ultrasound and clinical features of hip involvement in patients with gout. Joint Bone Spine 2019; 86: 633-666.

66. Cazenave T, Martire V, Reginato AM, Gutierrez M, Waimann CA, Pineda C et al.: Reliability of OMERACT ultrasound elementary lesions in gout: results from a multicenter exercise. Rheumatol Int 2019; 39: 707-713.

67. Murayama M, Nishida M, Kudo Y, Deguchi T, Marukawa K, Fujieda Y et al.: Case with long-standing gout showing various ultrasonographic features caused by monosodium urate monohydrate crystal deposition. Modern Rheumatology Case Rep 2020; 4: 110-115.

68. Micu MC, Dogaru BG: Monstrous gout devastating hands and feet. Clin Rheumatol 2019; 38: 3309-3310.

69. Persons B, Kissin EY: Scruples over speckles. J Med Ultrasound 2020 28: $179-180$.

70. Sakellariou G, Scirè CA, Adinolfi A, Batticciotto A, Bortoluzzi A, Delle Sedie A et al:: Differential diagnosis of inflammatory arthropathies by musculoskeletal ultrasonography: a systematic literature review. Front Med 2020; 7: 141.

71. Scirocco C, Rutigliano IM, Finucci A, Iagnocco A: Musculoskeletal ultrasonography in gout. Med Ultrason 2015; 17: 535-540. 